\title{
Assessment of Rancidity and Other Physicochemical Properties of Edible Oils (Mustard and Corn Oils) Stored at Room Temperature
}

\author{
Susan Okparanta*, Victoria Daminabo, Leera Solomon \\ Department of Science Laboratory Technology, School of Science and Technology, Captain Elechi Amadi Polytechnic, Rumuola, Port \\ Harcourt, Nigeria \\ Email address: \\ Oparasusan2211@gmail.com (S. Okparanta) \\ ${ }^{*}$ Corresponding author
}

\section{To cite this article:}

Susan Okparanta, Victoria Daminabo, Leera Solomon. Assessment of Rancidity and Other Physicochemical Properties of Edible Oils (Mustard and Corn Oils) Stored at Room Temperature. Journal of Food and Nutrition Sciences. Vol. 6, No. 3, 2018, pp. 70-75.

doi: $10.11648 /$ j.jfns.20180603.11

Received: April 9, 2018; Accepted: April 28, 2018; Published: May 28, 2018

\begin{abstract}
Oils may go rancid and develop an unpleasant odor and flavor if incorrectly stored. The main factors that cause rancidity (in addition to moisture, bacteria and enzymes) are light, heat, air and some types of metals. Rancid oil forms harmful free radicals in the body, which are known to cause cellular damage and have been associated with diabetes, Alzheimer's disease and other conditions. Rancid oils can also cause digestive distress and deplete the body of vitamins B and E. Their chemical edible is comprised of saturated and unsaturated fatty acids and glycerides. Temperature affects the quality of edible oils. When edible oils are exposed to high temperatures, unpleasant odours and flavours could result from the deterioration its fatty or oilly portion. The study aimed at assessing rancidity and other physicochemical properties of edible oils (Mustard and Corn oils) at room temperature. Physicochemical properties of edible oils was assesses using standard analytical procedures. The results obtained gave values of density as $8.8512 \mathrm{~g} / \mathrm{mL}$ for Cord oil (CO) and $9.8779 \mathrm{~g} / \mathrm{mL}$ for mustard oil (MO) while values of 111.601 millipoise and 116.832 millipoise were obtained for viscosity. The temperatures were $140.02^{\circ} \mathrm{C}$ and $169.4^{\circ} \mathrm{C}$ for $\mathrm{CO}$ and $\mathrm{MO}$ respectively. Saponification value ranged from $152.7 \mathrm{mg}$ for $\mathrm{CO}$ to $124.8 \mathrm{mg} \mathrm{MO}$. Iodine value gave $16.56 \mathrm{~g}$ for $\mathrm{CO}$ and $8.11 \mathrm{~g}$ in MO respectively while peroxide value recorded $213.459 \mathrm{meq} / \mathrm{kg}$ in CO and $12.8411 \mathrm{meq} / \mathrm{kg}$ for $\mathrm{MO}$. The quality of edible oil should be regularly monitored to avoid the use of abused oil due to the health consequences of consuming foods fried in degraded oil and also, to minimize the production costs associated with early disposal of the frying medium.
\end{abstract}

Keywords: Edible Oils, Corn Oil, Mustard Oils, Rancidity, Temperature, Deterioration

\section{Introduction}

Edible oils are vital constituents of our daily diet, which provide energy, essential fatty acids and serve as a carrier of fat soluble vitamins. Corn oil which is obtained from seeds of Zea mays is an important component usually used as food and also as a vehicle in pharmaceutical formulations such as in suspensions and emulsions [1]. Mustard oil from Brassica nigra has $30 \%$ protein, calcium, phytins, phenolics and natural anti-oxidants. Mustard oil contains a high amount of mono-unsaturated fatty acids and a good ratio of polyunsaturated fatty acids, which is good for the heart. Mustard oil contains the least amount of saturated fatty acids, making it safe for heart patients. Rancidity is a term generally used to denote unpleasant odours and flavours in foods resulting from deterioration in the fat or oil portion of a food. Three different mechanisms of rancidity may occur. Lipids and triacylglycerol naturally occur in oils and fats. Their chemical composition contains saturated and unsaturated fatty acids and glycerides.

Different physical and chemical parameters of edible oil were used to monitor the compositional quality of oils [2, 3]. These physico-chemical parameters include iodine value (IV), saponification value (SV), viscosity, density and peroxide value (PV). Edible oils are one of the main constituents of the diet used for cooking purposes. Several researchers studied the impact of temperature on the stability; viscosity, peroxide 
value, and iodine value to assess the quality and functionality of the oil [4-6]. Plate 1 shows the two edible oils used, (a) Mustard oil, (b) Corn oil used in this research study.

Deep frying is one of the most common methods used for the preparation of food. Repeated frying causes overall oxidative and thermal reactions which results in change in the physicochemical, nutritional and sensory properties of the oil [7]. During frying, due to hydrolysis, oxidation and polymerization processes the composition of oil changes which in turn changes the flavour and stability of its compounds [8]. During deep frying different reactions depend on some factors such as replenishment of fresh oil, frying condition, original quality of frying oil and decrease in their oxidative stability [9]. Atmospheric oxygen reacts instantly with lipid and other organic compounds of the oil to cause structural degradation in the oil which leads to loss of quality off odour and is harmful to human health [10].

Therefore, it is essential to monitor the quality of oil to avoid the use of abused oil due to the health consequences of consuming foods fried in degraded oil, to maintain the quality of fried foods and to minimize the production costs associated with early disposal of the frying medium [11]. Rancid oil forms harmful free radicals in the body, which are known to cause cellular damage and have been associated with diabetes, Alzheimer's disease and other conditions.

Rancid oils can also cause digestive distress and deplete the body of vitamins B and E. In his book " 8 Weeks to Optimum Health", Dr. Andrew Weil says rancid oil can also cause damage to DNA, accelerate aging, promote tissue degeneration and foster cancer development [12]. The study aimed at assessing rancidity and other physicochemical properties of edible oils (Mustard and Corn oils) at room temperature. Rancidity is a term generally used to denote unpleasant odours and flavours in foods resulting from deterioration in the fat or oil portion of a food.

Three different mechanisms of rancidity may occur. These are oxidative, hydrolytic, and ketonic. Oxidative rancidity arises from the decomposition of peroxides. Peroxides are the result of the oxidation of unsaturated fats. The products resulting from the decomposition of peroxides include aldehydes, ketones, and hydrocarbons.

These help to produce the flavours and odours associated with oxidative rancidity. The abnormal characteristics of a product that has undergone oxidative rancidity are paint like or acrid (burning) odour and an abnormal (rancid) taste. The colour of a food item is not normally changed due to this deteriorative process. The texture of a food product is not affected by the deteriorative condition.

\subsection{Microbial Decomposition of Fats, Oils and Other Lipids}

Rancidity could also be as a result of microbial decomposition of fats, oils and other lipids. When these processes occur in food, undesirable odours and flavors can result. Microbial contamination of food such as edible oil is the most common health risk. Edible oil is prone to contamination by microorganisms found in the environment, raw materials and equipment used for the processing, as well as those used for storage and distribution. Edible oil is prone to contamination by microorganisms found in the environment, raw materials and equipment used for the processing, as well as those used for storage and distribution.

This problem is repeatedly observed in many edible oil market areas. Food handlers with poor personal hygiene and inadequate knowledge on food safety and quality could be the source of food pathogen. The microbial isolates implicated in rancid oils are Staphylococcus aureus, Pseudomonas aerugenosa, Klebsiella pneumonie, Shigella sonnei, Penicillium chrisoginum, Aspergillus niger, Aspergillus flavus, Aspergillus fumigatus, Aspergillus versicolor, Fusarium oxisporium, Candida albicans and Mucor spp. The poor microbial and physico-chemical properties are indicator of unhygienic handling practice and processing methods of edible oil sold in the retail markets.

\subsection{Health Effects}

While rancid oil may taste bad, it doesn't normally make you sick, at least not in the short term. Rancid oil does contain free radicals that might increase your risk of developing diseases such as cancer or heart disease down the road. Rancid oils may produce damaging chemicals and substances that may not make you immediately ill, but can cause harm over time. Chemicals such as peroxides and aldehydes can damage cells and contribute to atherosclerosis. Free radicals produced by rancid oil can also damage DNA in cells. Produced by toxins as well as by normal bodily processes, free radicals can cause damage to arteries as well act as carcinogens, substances that can cause cancer.

If oxidative rancidity is present in severe quantities, a potential health hazard may exist. High levels of malonaldehyde are found in rancid foods. Malonaldehyde is a decomposition product of polyunsaturated fatty acids. This chemical has been reported to be carcinogenic and a potential health hazard does exist. Eating rancid oil will expose you to accelerated aging, raised cholesterol levels, obesity and weight gain. Daily consumption increases the risk of degenerating diseases such as cancer; diabetes; Alzheimer's disease; and atherosclerosis, a condition in which artery walls thicken due to a buildup of fatty materials. According to a study from the University of Basque Country, the breakdown rate and total formation of toxic compounds depends on the type of oil and temperature. Initially, the oil decomposes into hydroperoxides, then into aldehydes.

\subsection{Testing for Rancidity}

Depending on the type of oil, its age, storage conditions, etc., one or more of the following tests by themselves or combined are good indicators of oil rancidity:

\subsection{Peroxides Value}

The peroxides value is the quantity of hydro peroxides (expressed as meq $\mathrm{O} 2 / \mathrm{kg}$ ) present in the oil that have formed through oxidation during its processing and/or storage. This 
value is the primary measurement of oils rancidity and it gives us an idea of oils' freshness and storage conditions. The peroxides value will increase during the first part of the life of oils and it will then decrease in more advanced stages of oxidation when more oxidated substances are produced. These new substances are responsible for colour and aroma changes associated with rancidity.

If we suspect that the oil could be close to this stage other complementary analysis such as UV absorption are recommended. Based on international rules (IOC, Codex) extra virgin olive oils must show a peroxides value under 20 . Nonetheless, it is expected that fresh and well processed oils should show peroxides value less than 12 .

\subsection{UV Coefficients (K270 \& K232)}

The determination of the specific spectrophotometric extinction in ultraviolet at 232 and $270 \mathrm{~nm}$ provides a measurement of the state of oxidation of the oils and storage conditions. These methods are based on the properties of conjugated dienes and trienes to absorb UV radiation in those wave length ranges. Higher than normal values of K 270 would indicate an advanced oxidation stage or even a possible adulteration with refined oil. Extra virgin olive oils should have a K 232 below 2.50 and $\mathrm{K} 270$ below 0.22 . K 270 and K 232 in freshly produced oils hardly ever exceed values of 0.17 and 2.00 respectively.

\subsection{Determination of the Degradation Products of Chlorophylls $a$ and $a^{\prime}$ (Pheophytinsa, $a^{\prime}$ and Pyropheophytins)}

This method is based on measuring the dynamics of some chlorophyll pigments (pyropheophytina andpheophytins a and a') in olive oils. The PPPs Ratio shows a very good performance as indicator of overall olive oil quality and freshness showing better correlation with organoleptic scoring than any of the traditional IOC methods.

There is no evidence of initial varietal or environmental influence of this test. Freshly produced oils have PPPs levels below $0.5 \%$, this value increases over time and technical evidence shows that when those levels exceed the limits set by the Australian Standard 5264-2011 of 17\%, the oil is more than 2-2.5 years old and rancid.

\subsection{Determination of Relative Amounts of 1,2-and 1,3-Diacylglycerols or DAGs}

This method is based on the fact that in virgin olive oils, DAGs are present in a range of 1 to $3 \%$ and they are found as 1,2- and 1,3- isomers. The 1,2- isomers are attributed to the incomplete biosynthesis of triacylglycerols (TAGs), whereas the 1, 3- isomers are attributed to enzymatic or chemical hydrolysis of TAGs occurring before or during the oil extraction.

Consequently, freshly made olive oils from healthy olive fruits contain almost solely 1,2 DAGs; on the other hand, those coming from poor quality fruits show a significant increase of 1,3- isomers. The percentage of 1, 2 DAGs decreases over time and technical evidence shows that when those levels fall below the limits set by the Australian Standard 5264-2011 of $35 \%$, the oil is more than 2-2.5 years old and rancid.

\section{Materials and Methods}

Hydrochloric acid $(\mathrm{HCl})$, sodium hydroxide $(\mathrm{NaOH})$, potassium hydroxide $(\mathrm{KOH})$, idobromine $(\mathrm{IBr})$, sodium thiosulphate $\left(\mathrm{Na}_{2} \mathrm{~S}_{2} \mathrm{O}_{3}\right)$, potassium iodide $(\mathrm{KI})$, and acetic acid $\left(\mathrm{CH}_{3} \mathrm{COOH}\right)$ were of $\mathrm{A}$. R Grade and purchased from Merck Darmstadt Germany. Processed Corn oil and Mustard oil were purchased from a supermarket in Port Harcourt, Rivers State.

\subsection{Density and Viscosity Measurement}

Densities of oil samples before and after frying were measured by an R. D bottle with a capacity of $10 \mathrm{~mL}$. The viscosity of the edible oil samples before and after frying was measured by an Ostwald Viscometer techniconominal constant0.05 Cs/c, ASTMAD 445 England. The flow time of oil samples were recorded with a stop watch (Japan, CBM, and Corp QSQ) least count $\pm 0.01 \mathrm{~s}$.

\subsection{Saponification Value Measurement}

The saponification value is determined by taking $1.0 \mathrm{~g}$ of oil sample in a conical flask to which is added $15 \mathrm{~mL} 1 \mathrm{~N}$ $\mathrm{KOH}$ and $10 \mathrm{~mL}$ of distilled water and heated under a reserved con- denser for 30-40 min to ensure that the sample was fully dissolved. After this sample was cooled, phenolphthalein was added and titrated with $0.5 \mathrm{M}$ of $\mathrm{HCl}$ until a pink endpoint was reached. A blank was determined with same time conditions.

\subsection{Iodine Value (IV) Measurement}

A known weight of the oil sample is treated with an excess of iodobromine (IBr) in glacial acetic acid. Unreacted iodobromine is reacted with potassium iodide which converts it to iodine. The iodine concentration is then determined by titration with standard sodium thiosulphate.

$$
I V^{1} / 4 \text { ðb-vPxNx126:9x100=wx1000. ð1P }
$$

Where; $b$ quantity of sodium thiosulphate used for blank, $v$ is quantity of thiosulphate, Nisthe normality of thiosulphate solution, $w$ is the wt of the oil sample and 126.9 is molecular weight of iodine.

\subsection{Peroxide Value Measurement}

Peroxide value is a measure of peroxides contained in the oil. PV is determined by measuring iodine released from potassium iodide. A known measured weight of oil samples is dissolved in acetic acid then chloroform and saturated KI mixture area dded to the sample and the amount of iodine liberated from KI by the oxidative action of peroxides present in the oil is determined by titration with standard sodium thiosulphate using starch solution as an indicator. 
Titration performed forblanks [13].

\section{Results and Discussion}

The quality of Corn and Mustard oils was analyzed by evaluating physicochemical properties such as density, viscosity, boiling point, peroxide, iodine and saponification values. The results obtained gave values of density as $8.8512 \mathrm{~g} / \mathrm{mL}$ for Cord oil and $9.8779 \mathrm{~g} / \mathrm{mL}$ for Mustard oil while values of 111.601millipoise and 116.832 millipoise were obtained for viscosity [14]. The boiling temperatures were $140.02^{\circ} \mathrm{C}$ and $169.4^{\circ} \mathrm{C}$ for Corn oil and Mustard oil respectively.

Furthermore, the saponification value ranged from 152.7 $\mathrm{mg}$ for corn oil to $124.8 \mathrm{mg}$ for mustard oil. These parameters help in assaying rancid in the edible oils. Hence, Iodine value indicated $16.56 \mathrm{~g}$ (corn oil) and $8.11 \mathrm{~g}$ (mustard oil). The peroxide values were $213.459 \mathrm{meq} / \mathrm{kg}$ in cord oil and $12.8411 \mathrm{meq} / \mathrm{kg}$ for mustard oil respectively.

Oils with lower values of viscosity and density are highly appreciable to consumers. In order to design an advanced technological process these properties are very important parameters. Figure 1 show the physicochemical properties of the oils at room temperature $\left(35 \pm 2^{\circ} \mathrm{C}\right)$.

Figure 1 show that at room temperature, the viscosity in
Mustard oil was higher when compared to the value obtained for Corn oil. Mustard oil had high boiling point compared to Cornoil which had lower boiling point. It explains that the viscosity and density decreases with an increase in unsaturation and increases with high saturation and polymerization [15].

Viscosity also depends on sheer stress and temperature. Sheer stress does not have much effect on the storage of oils which are used for edible purposes but the temperature does affect it. Results tabulated in Table 1indicated that an increase in viscosity for Cornoil while a decrease in viscosity was observed for Mustard oil at the same boiling point but at different frying times with a piece of potato.

When the temperature increases, the kinetic energy also increases which enhanced the movement of the molecules and reduces the intermolecular forces. The layers of the liquid easily pass over one another and thus contribute to the reduction of viscosity. This phenomenon has been reported by other workers since oil viscosity depends on molecular structure and decreases with the unsaturation of fatty acids [15]. The densities of both oils were decreased with the rise in temperature as well as when using the same oil for frying one time with a piece of potato.

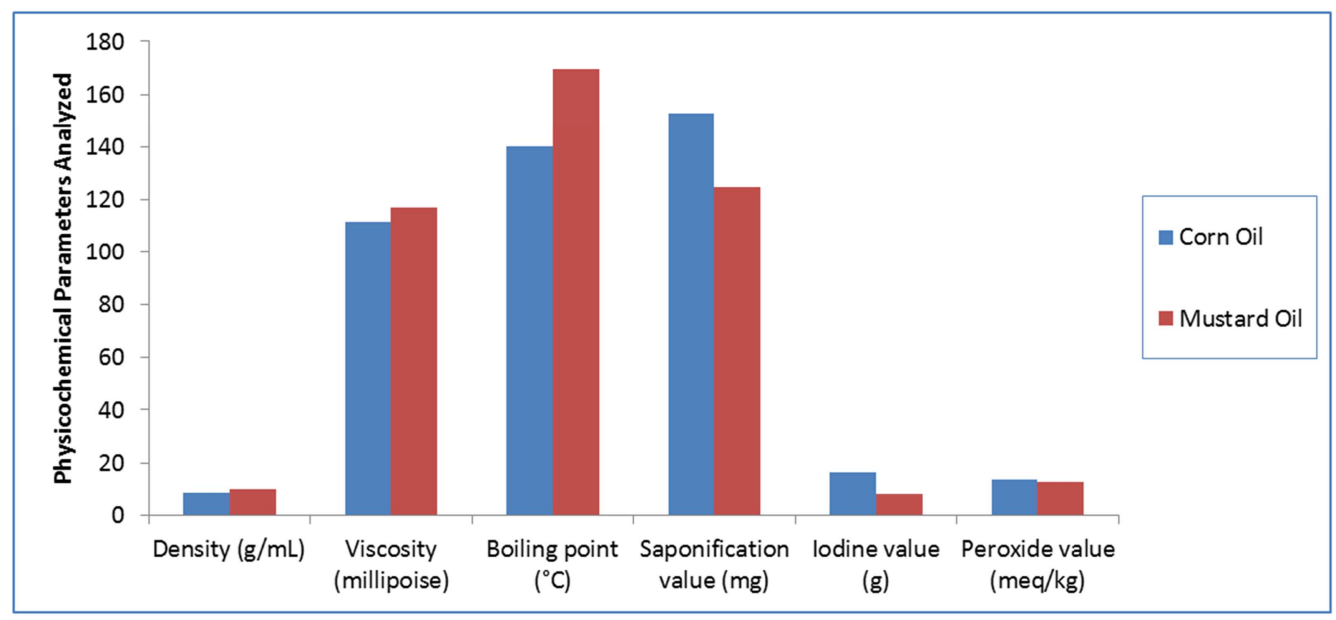

Figure 1. Physicochemical Properties of Two Vatieties of Edible Oils (Cord Oil And Mustard Oil)

The densities of oils were related to the standard range of $0.898-0.907 \mathrm{~g} / \mathrm{mL}$ approved by the Standard Organization of Nigeria (SON, 2000). TheresultstabulatedinTable1show that at room temperature of $35^{\circ} \mathrm{C}$ the values of the densities are $0.9694 \mathrm{~g} / \mathrm{mLand} 0.9223 \mathrm{~g} / \mathrm{mL}$ for Mustard oil and Cornoil respectively. It may be due to the pie bonds that make the bonding more rigid and rotation between $\mathrm{CAC}$ bonds becomes more strenuous. During frying thermo-oxidative or lipid oxidation and hydrolytic reactions take place that results in deterioration in quality of the edible oil $[16,17]$. The primary oxidation products that develop in triacylglycerol are hydroperoxides, which later break down to produce lower molecular weight compounds, such as free fatty acids, alcohols, aldehydes, and ketones, leading to a rancid product [18].

Table 1. Physicochemical Property of two Edible Oils at Room Temperature.

\begin{tabular}{lllll}
\hline \multirow{2}{*}{ S/No. } & \multirow{2}{*}{ Properties } & Unit & Edible Oils & Mustard Oil \\
\cline { 4 - 5 } & Density & $(\mathrm{g} / \mathrm{mL})$ & 8.8512 & 9.8779 \\
2. & Viscosity & $(\mathrm{millipoise})$ & 111.601 & 116.832 \\
3. & Boiling point & $\left({ }^{\circ} \mathrm{C}\right)$ & 140.02 & 169.4 \\
4. & Saponification value & $(\mathrm{mg})$ & 152.7 & 124.8 \\
5. & Iodine value & $(\mathrm{g})$ & 16.56 & 8.11 \\
6. & Peroxide value & $(\mathrm{meq} / \mathrm{kg})$ & 13.459 & 12.841 \\
\hline
\end{tabular}


Oils are mixtures of triglycerides (TGs) and their viscosity depends on the nature of the TGs present in the oil. The viscosity changed due to the different arrangement of the fatty acids on the glycerol backbone of the triglyceride molecule. Therefore, viscosity is related to the chemical properties of the oils such as chain length and saturation/unsaturation. Oxidation is a main deteriorative process which has an important implication in stipulations of the quality and value of fats and oils, particularly in relation to the off-flavors that develop as an outcome of autoxidation [19]. Normally, frying oils undergo extensive degradation and complex chemical transformations when heated [20]. The presence of air and water accelerated the deterioration of frying oil [21] and resulted in an increase in the number of polar molecules as confirmed by viscosity and density data of oils [22].

Peroxide value (PV) is used as a measure of the extent to which rancidity reactions have occurred during storage it could be used as an indication of the quality and stability of fats and oils [23]. The peroxide value was also found to increase with the storage time, temperature and con- tact with air of the oil samples [24]. The peroxide value determines the extent to which the oil has undergone rancidity. Peroxide value ranges are closely related to the standard value of 10 $\mathrm{meq} / \mathrm{kg}$ specified by Standard Organization of Nigeria [25] and Nigerian Industrial Standard (NIS, 1992). Saponification value (SV) is an index of average molecular mass of fatty acid in the oil sample. The SV value obtainedfor the oil samples in Figure 1 showed $153.8 \mathrm{mg} \mathrm{KOH} / \mathrm{g}$ for Corn oil and $125.6 \mathrm{mg} \mathrm{KOH} / \mathrm{g}$ for Mustard oil SON [25] and NIS[26].

The lower value of saponification values suggests that the mean molecular weight of fatty acids is lower or that the number of ester bonds is less. This implies that fat molecules did not interact with each other [27]. Iodine value (IV) measures the degree of unsaturation in a fat or vegetable oil. It determines the stability of oils to oxidation, and allows the overall unsaturation of the fat to be determined qualitatively $[28,29]$. It was observed that measured iodine values for Corn and Mustard oils are $15.96 \mathrm{~g}$ and $8.10 \mathrm{~g}$ respectively. These low iodine values may have contributed to its greater oxidative storage stability. The oxidative and chemical changes in oils during storage are characterized by an increase in free fatty acid contents and a decrease in the total unsaturation of oils [30].

All these physicochemical parameters are qualitative properties of oils and do not indicate the position of the double bonds or the amount of olefinic carbon that provides an overall status of unsaturation of the oils so it is not possible to point out the position of double bond(s) which are more susceptible to oxidation. The primary oxidation products that develop in triacylglycerol are hydroperoxides, which later break down to produce lower molecular weight compounds, such as free fatty acids, alcohols, aldehydes, and ketones, leading to a rancid product. The evaluated results of Mustard and Corn oils revealed that at the room temperature the degree of unsaturation is low and there are trans- hydroperoxide forms of esters present with primary oxidized products and as the sample is treated at higher temperatures up to their respective boiling points the decrease in $\% T$ indicates an increase in the absorbance of peroxides.

Secondary oxidation initiates the formation of secondary oxidation products and free fatty acids were also present. However the heights of some specific bands were noticeable indicating the difference in quality of the two different oil samples used in this present study.

\section{Conclusion and Recommendations}

\subsection{Conclusion}

Edible oil is prone to contamination by microorganisms found in the environment, raw materials and equipment used for the processing, as well as those used for storage and distribution. Rancid oils may produce damaging chemicals and substances that may not make you immediately ill, but can cause harm over time. Chemicals such as peroxides and aldehydes can damage cells and contribute to atherosclerosis. Free radicals produced by rancid oil can also damage DNA in cells. Produced by toxins as well as by normal bodily processes, free radicals can cause damage to arteries as well act as carcinogens, substances that can cause cancer. If oxidative rancidity is present in severe quantities, a potential health hazard may exist.

High levels of malonaldehyde are found in rancid foods. Malonaldehyde is a decomposition product of polyunsaturated fatty acids. Edible oils are one of the main constituents of the diet used for cooking purposes. Oils with lower values of viscosity and density are highly appreciable to consumers as they signify good quality fresh products. Temperature affects the quality of edible oils. The effect of temperature on the physicochemical characteristics and rancidity of two edible oils (corn and mustard oils) were analyzed. Results revealed that due to the temperature change in the oil there is a notable difference in the spectral band which showed that the proportions of the fatty acids were changed and thus, becoming soured or rancid.

\subsection{Recommendations}

The public should be aware that exposing edible oils to high temperatures for long periods of time could result to unpleasant odours and flavours in oils resulting from deterioration in the fat or oil portion of the edible oils. The abnormal characteristics of a product that has undergone oxidative rancidity are paint like or acrid (burning) odour and an abnormal (rancid) taste. The colour of edible oil is not normally changed due to this deteriorative process. The texture of edible oil product was not affected by the deteriorative condition due to temperature changes. 


\section{References}

[1] Alvarez, A. M. B., Rodr1'guez, M. L. G., 2000. Lipids in pharmaceuticaland cosmetic preparations. Grasas Aceites 51, 74-96.

[2] Ceriani, R., Paiva, F. R., Alves, C. B. G., Batista, E. A. C., Meirelles, A. J. A., 2008. Densities and viscosities of vegetable oils of nutritional value. J. Chem. Eng. Data 53 (8), $1846-1853$.

[3] Mousavi, K., Shoeibi, S., Ameri, M., 2012. Effects of storage conditions and PET packaging on quality of edible oils in Iran. Adv. Environ. Biol. 6 (2), 694-701.

[4] Farhoosh, R., Moosai, S. M. R., Sharif, A., 2008. Investigation onfrying oils quality in terms of color index, refractive index and viscosity during frying process. J. Food Sci. Tech. 5 (1):13-19.

[5] Li, H., Zhou, G., Zhang, H., He, Y., 2010. Chemical constituents and biological activities of saponin from the seed of Camellia oleifera. Sci. Res. Essays 5 (25), 4088-4092.

[6] Jinfeng, P., Huixing, S., Juan, Y., Yong, K. L., 2011. Changes in physiochemical properties of Myofibrillar protein from Silver Carp (Hypophthal michthysmollitrix) during heat treatment. J. FoodBiochem. 35, 939-952.

[7] Che Man, Y. B., Jasvir, I., 2000. Effect of rosemary and sage extracts on frying performance of refined, bleached and deodorized (RBD) palmolein during deep fat frying. Food Chem. 69, 301-307.

[8] Gloria, H., Aguilera, J. M., 1998. Assessment of the quality of heated oils by differential scanning calorimetry. J. Agric. Food Chem. 46, 1363-1368.

[9] Choe, E., Min, D. B., 2007. Chemistry of deep-fat frying oils. J. Food Sci. 72, 77-86.

[10] Bhattacharya, A. B., Sajilata, M. G., Tiwari, S. R., Singhal, R., 2008. Regeneration of thermally polymerized frying oils with adsorbents. Food Chem. 110, 562-570.

[11] Vijayan, J., Slaughter, D. C., Paul, S. R., 1996. Optical properties of corn oil during frying. Int. J. Food Sci. Technol. $31,353-358$.

[12] Che Man, Y. B., Syahariza, Z. A., Rohman, A., 2010. Fourier trans-form infrared (FTIR) spectroscopy: development, techniques, and application in the analyses of fats and oils. In: Ress, Oliver J. (Ed.), Fourier Transform Infrared Spectroscopy. Nova Science Publishers, New York, pp. 1-36.

[13] AOAC, 1984. Official Methods of Analysis. Association of OfficialAnalytical Chemists, Washington, DC.

[14] Singh, P. R., Gupta, D. S., Bajpai, K. S., 1981. In: Experimental OrganicChemistry, vol. 2. Tata McGraw-Hill, p. 301.
[15] Kim, J., Kim, D. N., Lee, S. H., Yoo, S. H., Lee, S., 2010. Correlation offatty acid composition of vegetable oils with rheological behaviorand oil uptake. Food Chem. 118, 398-402.

[16] Romero, A., Cuesta, C., Sa'nchez-Muniz, F. J., 2000. Cyclic fatty acid monomers and thermoxidative alteration compounds formed during frying of frozen foods in extra virgin olive oil. J. Am. Oil Chem. Soc. 77, 1169-1175.

[17] Paul, S., Mittal, G. S., 1997. Regulating the use of degraded oil/fat in deep fat/oil food frying. Crit. Rev. Food Sci. Nutr. 37, 632-662.

[18] Barthel, G., Grosch, W., 1974. Peroxide value determination: comparison of some methods. J. Am. Oil Chem. Soc. 51, 540544.

[19] Xiuzhu, Yu, Van De Voort, F. R., Sedman, J., 2007. Determination ofperoxide value of edible oils by FT-IR spectroscopy with the use of the spectral reconstitution technique. Talanta 74, 241-246.

[20] Guillen, M. D., Cabo, N., 2000. Some of the most significant changes in the Fourier transform infrared spectra of edible oils under oxidative conditions. J. Sci. Food Agric. 80, 2028-2036.

[21] Clark, W. L., Serbia, G. W., 1991. Safety aspects of frying fats and oils. Food Technol. 45 (2), 84-89.

[22] White, P. J., 1991. Methods for measuring changes in deep-fat frying oils. Food Technol. 45 (2), 75-80.

[23] Ekwu, F. C., Nwagu, A., 2004. Effect of processing on the quality of cashew nut oils. J. Sci. Agric. Food Tech. Environ. $4,105-110$.

[24] Knothe, G., Dunn, R., 2003. Dependence of oil stability index of fatty compounds on their structure and concentration and presence of metals. J. Am. Oil Chem. Soc. 80, 1021-1026.

[25] SON, 2000. Standard Organization of Nigeria. Standards for Edible Refined Palm Oil and Its Processed form, pp. 2-5.

[26] NIS, 1992. Nigerian Industrial Standards. Standard for Edible Vegetable Oil, pp. 5-12.

[27] Denniston, K. J., Topping, J. J., Cariet, R. L., 2004. In: General Organic and Biochemistry, fourth ed. McGraw Hill Companies, New York, pp. 432-433.

[28] AOCS, 1993. In: Official Methods and Recommended Practice of the American oil Chemist Society, fifth ed. AOAC Press, Champaign, IL.

[29] Asuquo, J. E., Anusiem, A. C. I., Etim, E. E., 2012. Extraction and characterization of rubber seed oil. Int. J. Mod. Chem. 1 (3), 109- 115.

[30] Perkin, E. G., 1992. Effect of lipid oxidation on oil and food quality in deep frying. In: Angels, A. J. S. (Ed.), Lipid Oxidation in Food, Chapter 18, ACS Symposium Series no. 500 ACS, American Chemical Society, Washington DC, pp. 310-321. 